\title{
Prevalence, Characteristics, Risk Factors, and Impact of Intestinal Parasitic Infections on School Children in Jeddah, Western Saudi Arabia
}

\author{
Marwan A. Bakarman ${ }^{1}$, Moustafa A. Hegazi ${ }^{2,3,{ }^{*}}$, Nadeem S. Butt ${ }^{1}$ \\ ${ }^{1}$ Department of Family and Community Medicine, Faculty of Medicine in Rabigh, King Abdulaziz University, Jeddah, Saudi Arabia \\ ${ }^{2}$ Department of Pediatrics, Faculty of Medicine in Rabigh, King Abdulaziz University, Jeddah, Saudi Arabia \\ ${ }^{3}$ Department of Pediatrics, Mansoura University Children's Hospital, Mansoura, Egypt
}

\section{ARTICLE INFO}

Article History

Received 24 June 2017

Accepted 16 January 2018

Keywords

Jeddah

intestinal parasitic infections

prevalence

risk factors

school children

\begin{abstract}
Intestinal Parasitic Infections (IPIs) are a major public health problem worldwide, especially among children with a need for periodical evaluation of prevalence and risk factors to adopt an appropriate prevention strategy. This cross-sectional prospective study was conducted to identify prevalence, risk factors, characteristics, and impact of IPIs on school children in different regions of Jeddah, Saudi Arabia. Children were recruited from randomly selected schools. Questionnaires were distributed to students and filled by their parents to collect relevant information about sociodemographic, environmental, and hygienic living conditions. Stool samples and anthropometric measurements as indicators of nutritional status were collected from students who agreed to participate in the study. Fecal samples were examined by direct smear and formol-ether concentration method. Out of 581 collected stool samples, only 31 (5.3\%) samples were positive for IPIs especially Blastocystis hominis (10 samples) and Giardia lamblia (six samples). The only two significant risk factors associated with IPIs were drinking water from tanks [odds ratio (OR): $3.35,95 \%$ confidence interval (CI): 1.60-6.99, $p=0.001$ ] and washing hands with only water (OR: $2.63,95 \%$ CI: 1.17-5.93, $p=$ 0.03). There was no significant impact of IPIs on growth parameters or level of children's academic performance.
\end{abstract}

(C) 2019 Atlantis Press International B.V.

This is an open access article distributed under the CC BY-NC 4.0 license (http://creativecommons.org/licenses/by-nc/4.0/).

\section{INTRODUCTION}

Intestinal Parasitic Infections (IPIs) constitute an important worldwide health problem, especially in children in developing countries, resulting in a significant illness in the form of either acute or chronic infections [1,2] but an accurate diagnosis is rarely performed [3]. Intestinal parasites are endemic in many parts of the world. In a rural area in China, about 33\% of preschool and $40 \%$ of school children were infected with soil-transmitted helminthes [4]. Moreover, endemic IPIs in the United States are even more frequent than is commonly perceived, and IPIs with Giardia, Cryptosporidium, and Dientamoeba were common among children, especially during the summer season. So, endemic IPIs in the United States are not uncommon but are understudied [5].

The effective policy of control and prevention of IPIs depends mainly on determination of local risk factors, particularly among high-risk groups. Severe malnutrition, poor socioeconomic standards, poor educational background, poor hygienic living conditions, and lack of proper personal and environmental sanitation, are the factors frequently related to increased rates of IPIs in school children [6-10].

"Corresponding author.Email: mhegazi712003@yahoo.co.uk, Postal Address: Faculty of Medicine in Rabigh, King Abdulaziz University, P.O. 80205, Jeddah, 21589
Intestinal Parasitic Infections affect children more than adults, resulting in malnutrition, malabsorption, growth retardation, and learning disabilities, especially in growing children. An association between IPIs and malnutrition was observed in preschool children in many parts of the world, especially the poorest areas $[11,12]$. Helminthic infections in children are associated with significant wasting and stunting [4]. Consequently, The World Health Organization (WHO) recommends treating all school children at regular intervals with deworming drugs in areas where helminth infection is common, to improve nutritional status, hemoglobin, cognition, and overall health of school children [13].

A few studies have been conducted in some regions of Saudi Arabia, such as Abha and Riyadh, to identify the prevalence of IPIs in stool samples of school children. The prevalence of IPIs ranged from about $24 \%$ in Abha to $34 \%$ in Riyadh. The most common pathogenic parasites detected were Giardia lamblia followed by Entamoeba histolytica. Hymenolepis nana was the commonest intestinal helminth, especially among children from lower social classes. In Riyadh, high infection rate was found in children aged below 12 years, urban areas, non-Saudis, and in people who were drinking water from tanks [14-16].

Regarding our locality of Jeddah, the prevalence of parasitic pathogens among preschool children suffering from acute diarrhea from December 1995 to October 1996 revealed that G. lamblia and 
E. histolytica were detected in $3.1 \%$ and $2.2 \%$, respectively, of 576 collected fecal samples, while Trichuris trichiura, H. nana, and Ascaris lumbricoides had a low prevalence of $0.7 \%$ for each [17]. Another study in Jeddah detected a prevalence rate of IPIs of $9.5 \%$ among primary school children and G. lamblia was the most commonly reported parasite [18]. The most recent study by Hegazi et al. [19] in 2013 showed that E. histolytica had a high prevalence of $20 \%$ and unusual presentation with severe clinical manifestations, and affected a high proportion of infants aged below 1 year, but this study was conducted among Saudi children hospitalized for acute diarrheal illness.

The prevalence of IPIs is variable among populations and even varies among regions of the same country. Therefore, there is a need for periodical evaluation of the local prevalence and risk factors of IPIs to adapt an appropriate control and prevention strategy.

Therefore, this study was conducted to identify current prevalence, characteristics, risk factors, and impact of IPIs on growth status and academic performance of school children in different regions of Jeddah, Western Saudi Arabia.

\section{MATERIALS AND METHODS}

\subsection{Study Design and Selection of Participants}

This cross-sectional study included primary and preparatory school children from randomly selected schools in different regions of Jeddah City (North, South, Middle, East, and West). Approval for this study was obtained from the Ethical Committee of the Faculty of Medicine, King Abdulaziz University, Rabigh. Permission to visit schools and collect stool samples from children was obtained from the Department of Planning, Development, Studies and Research of the General Directorate of Education in Jeddah.

A simple structured self-administered pretested questionnaire of two sections was designed and translated into Arabic by the research team. The questionnaire was based on the most relevant items to IPIs in the literature and taking into consideration the specificities of our local population. The first part of the questionnaire included a full explanation of the concept, objectives, and benefits of this study. We obtained prior written informed consent from parents of children participating in this study before requesting parents to complete the questionnaires and children to provide stool samples. The second part of the questionnaire contained information about the students, level of academic performance, as well as information about sociodemographics, environmental factors, behavioral habits, and hygienic living conditions. A code was given for each questionnaire to identify the school, region, and participant. The same code was labeled on the containers used for stool collection.

A group of healthcare workers and nurses of male and female school health units in different regions of Jeddah was trained on the methodology of collection of data and stool samples and obtaining growth parameters of weight, height, and Mid-Upper Arm Circumference (MUAC). Each randomly selected school was visited by the research team and healthcare workers to distribute the questionnaires and stool collection containers to students who were asked to provide the questionnaires completed by parents on the morning of the following day, after obtaining parental consent to participate in the study. Students whose parents gave consent and completed the questionnaires were asked to provide fresh stool samples in the morning just after their arrival at school. Weight, height, and MUAC of children who agreed and could provide stool samples were measured after delivery of stool samples. Anthropometric measurements as indicators of nutritional status were taken for the recruited children to assess the impact of IPIs on growth and nutritional status of school children included in this study.

\subsection{Method of Stool Examination}

The collected stool samples were examined at the Regional Laboratory in Jeddah; a special laboratory experienced in the detection of intestinal parasites. Freshly collected stool samples at schools were examined within $2 \mathrm{~h}$ of collection to maintain viability of trophozoites. Fecal samples were examined for ova, larvae, trophozoites, cysts, worms, and cellular components as white blood cells and red blood cells by direct saline smear under light microscopy and formol-ether concentration method.

\subsection{Formol-ether Concentration Technique}

This is the standard method for detection of IPIs previously used in many studies, especially among school children $[2,8-10,18]$. Two grams of fresh stool were added to 3 milliliters normal saline in a flat-bottomed tube and mixed well. The mixture was transferred to a centrifuge tube. Six milliliters of $10 \%$ formalin were added to the tube and left for $10 \mathrm{~min}$ for fixation. Then, 3 milliliters ether were added and the tube, which was capped and inverted to mix the contents. The tube was centrifuged at $70 \mathrm{~g}$ for $10 \mathrm{~min}$. After centrifugation, the tube was checked to see four layers. The top three layers were removed and the sediment was examined under a microscope.

\subsection{Sample Size and Study Power}

The sample size was calculated on the basis of mainly historical and published data on the prevalence of IPIs in the study area, conservatively estimated to be around $10 \%$. A sample size of 540 from a population of 500,000 achieves $80 \%$ power to detect a difference $4 \%$ between the hypothesized proportion of $10 \%$, and the alternative hypothesis that the population proportion is $14 \%$ using a two-sided, binomial hypothesis test with a target significance level $<0.05$ [20].

\subsection{Statistical Analysis}

Statistical analysis was conducted using (IBM Corporation, NY, USA) SPSS Statistics version 20. The qualitative data were presented in the form of frequencies and percentages while the quantitative data were represented by means and standard deviations. The comparison of qualitative data between groups was done by $\chi^{2}$ test and Fisher's exact test, while the comparison between means was done by independent samples $t$-test. Unadjusted odds ratios (ORs) with 95\% confidence intervals (CIs) were calculated to quantify risk of various factors associated with IPIs. Logistic regression was done to adjust for confounders and to determine the most significant risk factors associated with IPIs. Linear regression was done to see the effect of IPIs on anthropometric measurements adjusted for age. Significance was considered at $p<0.05$. 


\section{RESULTS}

Three thousand questionnaires were distributed to children at different schools from December 2015 to May 2016 but questionnaires and stool samples were collected from only 581 students (response rate 19.4\%). This number exceeded the 540 required total samples determined in the sample size of the study by 41 samples. So, the power of the study was increased to $85 \%$ (Figure 1 ).

Out of 581 collected stool samples, only 31 (5.3\%) samples were positive for IPIs. The detected IPIs included: Blastocystis hominis $(n=10)$, G. lamblia $(n=6)$, Endolimax nana $(n=5)$, Entamoeba coli $(n=4)$, and mixed infections with $B$. hominis, E. nana, and E. coli $(n=4)$, Chilomastix mesnili $(n=1)$ and H. nana $(n=1)$.

The 581 students from primary and preparatory schools who participated in this study included 446 (76.8\%) boys and $135(23.2 \%)$ girls with a mean and standard deviation of 11.69 \pm 1.84 years and age range of 6-16 years. Nonsignificant differences were found between students with and without IPIs regarding all studied demographic and socioeconomic risk factors (Table 1).

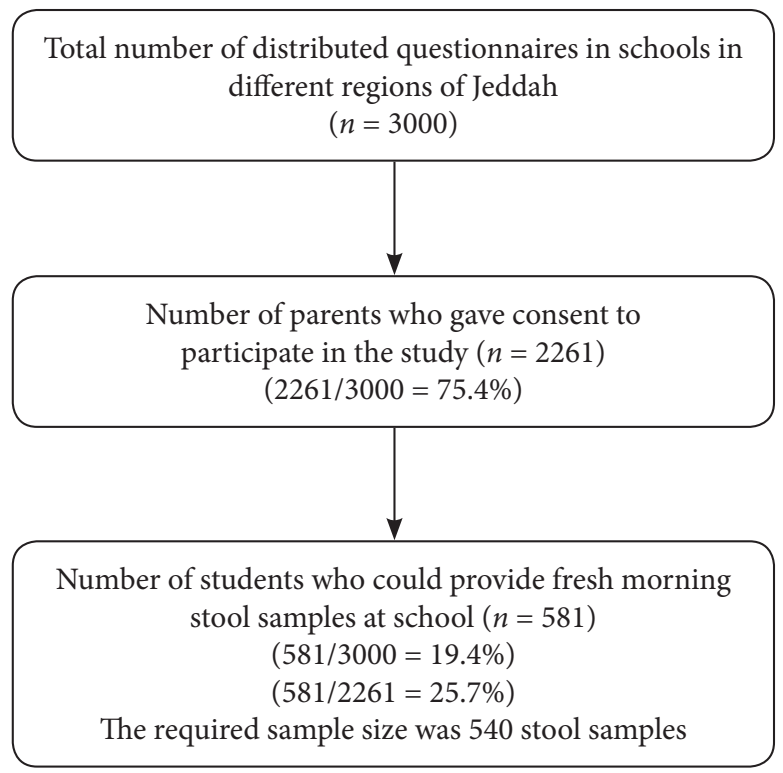

Figure 1 Study flowchart

Table 1 Comparison of demographic and socioeconomic data between students with and without intestinal parasitic infections

\begin{tabular}{|c|c|c|c|c|c|c|c|}
\hline & & \multirow{2}{*}{ Negative $(n=550)$} & \multirow{2}{*}{ Positive $(n=31)$} & \multirow{2}{*}{$p$} & \multirow{2}{*}{ OR } & \multicolumn{2}{|c|}{ 95\% CI for OR } \\
\hline & & & & & & LCL & UCL \\
\hline Student age years & Mean \pm SD (range) & $11.65 \pm 1.83(6-16)$ & $12.65 \pm 2.03(10-16)$ & $0.08^{\mathrm{a}}$ & $\mathrm{N} / \mathrm{A}$ & $\mathrm{N} / \mathrm{A}$ & $\mathrm{N} / \mathrm{A}$ \\
\hline \multirow[t]{2}{*}{ Student gender } & Male & $419(76.18)$ & $27(87.10)$ & $0.23^{\mathrm{b}}$ & 2.11 & 0.73 & 6.14 \\
\hline & Female & $131(23.82)$ & $4(12.90)$ & & & & \\
\hline \multirow{5}{*}{$\begin{array}{l}\text { Residence (location of } \\
\text { home in Jeddah) }\end{array}$} & East & $88(16.0)$ & $5(16.13)$ & $0.97^{c}$ & 1.02 & 0.35 & 3.03 \\
\hline & West & $58(10.54)$ & $4(12.90)$ & $0.72^{c}$ & 1.24 & 0.38 & 4.05 \\
\hline & Center & $113(20.55)$ & $9(29.03)$ & $0.44^{\mathrm{c}}$ & 1.43 & 0.58 & 3.56 \\
\hline & North & $93(16.91)$ & $2(6.45)$ & $0.22^{c}$ & 0.39 & 0.08 & 1.78 \\
\hline & South $^{\mathrm{d}}$ & $198(36.0)$ & $11(35.48)$ & & & & \\
\hline \multirow[t]{4}{*}{ Type of home } & Rented apartment & $416(75.64)$ & $24(77.41)$ & $0.31^{c}$ & 0.52 & 0.15 & 1.83 \\
\hline & Own apartment & $93(16.91)$ & $3(9.68)$ & $0.14^{\mathrm{c}}$ & 0.29 & 0.06 & 1.52 \\
\hline & Rented villa & $14(2.54)$ & $1(3.23)$ & $0.71^{\mathrm{c}}$ & 0.64 & 0.06 & 6.76 \\
\hline & Own villa ${ }^{\mathrm{d}}$ & $27(4.91)$ & $3(9.68)$ & & & & \\
\hline \multirow[t]{4}{*}{ Monthly income, SAR } & $<3000$ & $107(19.46)$ & $8(25.81)$ & $0.67^{c}$ & 1.26 & 0.44 & 3.59 \\
\hline & $3000-5000$ & $186(33.82)$ & $12(38.71)$ & $0.86^{c}$ & 1.09 & 0.42 & 2.84 \\
\hline & $5000-10,000$ & $139(25.27)$ & $4(12.90)$ & $0.26^{c}$ & 0.49 & 0.14 & 1.71 \\
\hline & $>10,000^{\mathrm{d}}$ & $118(21.45)$ & $7(22.58)$ & & & & \\
\hline \multirow[t]{6}{*}{ Paternal education level } & Illiterate & $18(3.27)$ & $1(3.23)$ & $0.56^{c}$ & 0.47 & 0.04 & 5.70 \\
\hline & Primary school & $58(10.55)$ & $2(6.45)$ & $0.24^{c}$ & 0.29 & 0.04 & 2.24 \\
\hline & Preparatory school & $102(18.55)$ & $7(22.58)$ & $0.52^{c}$ & 0.58 & 0.11 & 3.05 \\
\hline & Secondary school & $202(36.73)$ & $11(35.48)$ & $0.34^{c}$ & 0.46 & 0.10 & 2.26 \\
\hline & University & $153(27.82)$ & $8(25.81)$ & $0.33^{c}$ & 0.44 & 0.09 & 2.27 \\
\hline & Higher education $^{\mathrm{d}}$ & 17 (3.09) & $2(6.45)$ & & & & \\
\hline \multirow[t]{6}{*}{ Maternal education level } & Illiterate ${ }^{\mathrm{d}}$ & $35(6.36)$ & $3(9.68)$ & & & & \\
\hline & Primary school & $93(16.91)$ & $6(19.35)$ & $0.70^{c}$ & 0.75 & 0.18 & 3.18 \\
\hline & Preparatory school & $106(19.27)$ & $3(9.68)$ & $0.19^{c}$ & 0.33 & 0.06 & 1.71 \\
\hline & Secondary school & $176(32.0)$ & $12(38.71)$ & $0.73^{c}$ & 0.80 & 0.21 & 2.97 \\
\hline & University & $131(23.82)$ & $7(22.58)$ & $0.51^{c}$ & 0.62 & 0.15 & 2.54 \\
\hline & Higher education & $9(1.64)$ & $0(0)$ & & & & \\
\hline \multirow[t]{5}{*}{ Paternal occupation } & None & $71(12.91)$ & $3(9.68)$ & $0.50^{c}$ & 0.61 & 0.15 & 2.54 \\
\hline & Skilled worker & $89(16.18)$ & $6(19.35)$ & $0.97^{c}$ & 0.98 & 0.30 & 3.15 \\
\hline & Unskilled worker & $243(44.18)$ & $13(41.94)$ & $0.62^{c}$ & 0.78 & 0.29 & 2.10 \\
\hline & Semiprofessional & $60(10.91)$ & $3(9.68)$ & $0.66^{c}$ & 0.73 & 0.17 & 3.01 \\
\hline & Professional $^{\mathrm{d}}$ & $87(15.82)$ & $6(19.35)$ & & & & \\
\hline
\end{tabular}

andependent samples $t$-test; ' Fisher's exact test; 'Wald $\chi^{2}$ test; ${ }^{\mathrm{d}}$ Reference category; Data are presented as $n$ (\%); CI, confidence interval; LCL, lower confidence limit; N/A, not applicable; OR, odds ratio; SAR, Saudi riyal; SD, standard deviation; UCL, upper confidence limit. 
Regarding the clinical data, there was a nonsignificant difference in clinical symptoms relevant to IPIs, history of recurrent similar symptoms, and previously diagnosed and treated IPIs, between students with and without IPIs (Table 2). Out of 31 IPIs cases, 18 (58\%) were completely asymptomatic without any gastrointestinal (GI) symptom. The most common GI symptom in cases with IPIs was Recurrent Abdominal Pain (RAP) associated with B. hominis (two cases), E. coli (three cases), and E. nana (one case). Diarrhea was only reported in two cases; one with G. lamblia and the other with $B$. hominis. Anorexia was reported in three cases of G. lamblia; one with B. hominis, and one with E. coli (Table 2).

Nonsignificant differences were found between students with and without IPIs regarding source of water for cleaning, availability of water, and all studied behavioral variables (Tables 3 and 4). The only two significant risk factors associated with IPIs were drinking water from tanks (OR: 3.35, 95\% CI: 1.60-6.99, $p=0.001$; Table 3 ) and washing hands with only water (OR: 2.63, 95\% CI: $1.17-5.93, p=0.03$; Table 4 ). These two risk factors remained significant after adjustment for age and gender by logistic regression (Tables 3 and 4).

Table 2 Comparison of clinical data between students with and without intestinal parasitic infections

\begin{tabular}{|c|c|c|c|c|c|c|}
\hline & & \multicolumn{2}{|c|}{$\begin{array}{l}\text { Negative } \\
(n=550)\end{array}$} & \multicolumn{2}{|c|}{$\begin{array}{l}\text { Positive } \\
(n=31)\end{array}$} & \multirow{2}{*}{$p$} \\
\hline & & Number & $\%$ & Number & $\%$ & \\
\hline \multirow[t]{2}{*}{ Recurrent abdominal pains } & $\mathrm{No}^{\mathrm{a}}$ & 454 & 82.55 & 24 & 77.42 & $0.47^{\mathrm{b}}$ \\
\hline & Yes & 96 & 17.45 & 7 & 22.58 & \\
\hline \multirow[t]{2}{*}{ Abdominal distension } & $\mathrm{No}^{\mathrm{a}}$ & 482 & 87.64 & 28 & 90.32 & $0.92^{c}$ \\
\hline & Yes & 68 & 12.36 & 3 & 9.68 & \\
\hline \multirow[t]{2}{*}{ Nausea } & $\mathrm{No}^{\mathrm{a}}$ & 527 & 95.82 & 28 & 90.32 & $0.31^{\mathrm{c}}$ \\
\hline & Yes & 23 & 4.18 & 3 & 9.68 & \\
\hline \multirow[t]{2}{*}{ Vomiting } & $\mathrm{No}^{\mathrm{a}}$ & 538 & 97.82 & 29 & 93.55 & $0.34^{\mathrm{c}}$ \\
\hline & Yes & 12 & 2.18 & 2 & 6.45 & \\
\hline \multirow[t]{2}{*}{ Diarrhea } & $\mathrm{No}^{\mathrm{a}}$ & 519 & 94.36 & 29 & 93.55 & $0.99^{c}$ \\
\hline & Yes & 31 & 5.64 & 2 & 6.45 & \\
\hline \multirow[t]{2}{*}{ Anorexia } & $\mathrm{No}^{\mathrm{a}}$ & 490 & 89.09 & 26 & 83.87 & $0.52^{c}$ \\
\hline & Yes & 60 & 10.91 & 5 & 16.13 & \\
\hline \multirow[t]{2}{*}{ Blood in stools } & $\mathrm{No}^{\mathrm{a}}$ & 541 & 98.36 & 31 & 100 & \\
\hline & Yes & 9 & 1.64 & 0 & 0 & $0.99^{c}$ \\
\hline \multirow[t]{2}{*}{ Previous similar symptoms } & $\mathrm{No}^{\mathrm{a}}$ & 413 & 75.09 & 22 & 70.97 & $0.61^{\mathrm{b}}$ \\
\hline & Yes & 137 & 24.91 & 9 & 29.03 & \\
\hline \multirow[t]{2}{*}{ Previous treatment of IPIs } & $\mathrm{No}^{\mathrm{a}}$ & 502 & 91.27 & 29 & 93.55 & $0.98^{c}$ \\
\hline & Yes & 48 & 8.73 & 2 & 6.45 & \\
\hline
\end{tabular}

a Reference category; ${ }^{\text {PPearson's }} \chi^{2}$ test; ' Fisher's exact test.
There was no significant impact of IPIs on growth parameters of school children (Table 5). Also, there was no significant difference in the level of academic performance between children with and without IPIs $\left(\chi^{2}=2.67, p=0.10\right)$.

\section{DISCUSSION}

In this study, the prevalence of IPIs in school children from different regions in Jeddah was $5.3 \%$, which represented a significant decline from the last reported prevalence of $9.5 \%$ in 2004 [18] (with a decreased risk by 1.9, 95\% CI: $1.06-3.30, p=$ $0.03)$. This significant decrease in prevalence of IPIs can reflect better awareness of population, and remarkable improvements in socioeconomic, environmental, and hygienic living conditions of school children in Jeddah. This is supported by the facts that Jeddah, in the past decade, has received much attention and many governmental interventions, including projects for new well-planned residential districts with affordable and healthy housing with noticeable improvements in management of decomposition and leakage from the sewage network and contamination of groundwater resources. In addition, fair distribution of social, health, and all other services was evident in different regions of Jeddah.

The most common detected intestinal parasite was B. hominis (10 cases) with a prevalence of $1.7 \%$. However, this can be regarded as a low prevalence of $B$. hominis if compared with its higher prevalence in a previous Saudi study (17.5\%) [21], or in developing countries, where $B$. hominis has significantly higher prevalence compared with that in developed countries [22], and may even reach $100 \%$ in poorly developed countries [23]. The high prevalence in developing countries could be related to contamination of food or water supplies and poor hygienic conditions [22].

In our study, $B$. hominis infection was associated with RAP and anorexia in one student and RAP and diarrhea in another. Thus, most of $B$. hominis infections were asymptomatic. This may be explained by the fact that there is still controversy about the pathogenicity of $B$. hominis because this parasite is common in the healthy population without causing any symptoms, and can be considered as a commensal organism [24]. However, $B$. hominis may be considered a potentially pathogenic protozoon as it has been associated with watery diarrhea, fever, nausea, vomiting, anorexia, and abdominal pain, and it has also been linked to irritable bowel syndrome $[25,26]$. Therefore, the role

Table 3 Comparison of source of water-related factors between students with and without intestinal parasitic infections

\begin{tabular}{|c|c|c|c|c|c|c|c|c|c|}
\hline & & \multicolumn{2}{|c|}{ Negative $(n=550)$} & \multicolumn{2}{|c|}{ Positive $(n=31)$} & \multirow{2}{*}{$p$} & \multirow{2}{*}{ OR } & \multicolumn{2}{|c|}{ 95\% CI for OR } \\
\hline & & Number & $\%$ & Number & $\%$ & & & LCL & UCL \\
\hline \multirow[t]{2}{*}{ Source of drinking water } & Bottles $^{\mathrm{a}}$ & 389 & 70.73 & 13 & 41.94 & $0.001^{\mathrm{b}}$ & 3.35 & 1.60 & 6.99 \\
\hline & Tanks & 161 & 29.27 & 18 & 58.06 & $0.008^{c}$ & $2.88^{c}$ & $1.31^{\mathrm{c}}$ & $6.31^{\mathrm{c}}$ \\
\hline \multirow{2}{*}{ Source of water for cleaning } & Municipal $^{\mathrm{a}}$ & 498 & 90.55 & 30 & 96.77 & $0.41^{\mathrm{d}}$ & 0.32 & 0.04 & 2.38 \\
\hline & Private & 52 & 9.45 & 1 & 3.23 & & & & \\
\hline \multirow[t]{2}{*}{ Availability of water } & Always available ${ }^{\mathrm{a}}$ & 470 & 85.45 & 26 & 83.87 & $0.97^{\mathrm{d}}$ & 1.13 & 0.42 & 3.02 \\
\hline & Sometimes available & 80 & 14.55 & 5 & 16.13 & & & & \\
\hline
\end{tabular}

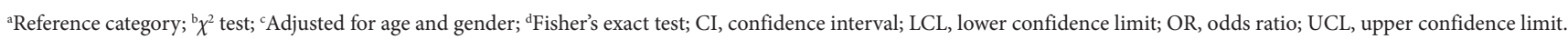


Table 4 Comparison of environmental conditions and behavioral health habits between students with and without intestinal parasitic infections

\begin{tabular}{|c|c|c|c|c|c|c|c|c|c|}
\hline & & \multicolumn{2}{|c|}{ Negative $(n=550)$} & \multicolumn{2}{|c|}{ Positive $(n=31)$} & \multirow{2}{*}{$p$} & \multirow{2}{*}{ OR } & \multicolumn{2}{|c|}{ 95\% CI for OR } \\
\hline & & Number & $\%$ & Number & $\%$ & & & LCL & UCL \\
\hline \multirow[t]{2}{*}{ Is home environment clean } & No & 7 & 1.27 & 0 & 0 & $0.99^{\mathrm{b}}$ & $\mathrm{N} / \mathrm{A}$ & & \\
\hline & Yes $^{\mathrm{a}}$ & 543 & 98.73 & 31 & 100 & & & & \\
\hline \multirow{2}{*}{$\begin{array}{l}\text { Is there any contact between student and } \\
\text { animals }\end{array}$} & $\mathrm{No}^{\mathrm{a}}$ & 512 & 93.09 & 28 & 90.32 & $0.75^{\mathrm{b}}$ & 1.44 & 0.42 & 4.97 \\
\hline & Yes & 38 & 6.91 & 3 & 9.68 & & & & \\
\hline \multirow{2}{*}{$\begin{array}{l}\text { Is there any contact between student and } \\
\text { stagnant water? }\end{array}$} & $\mathrm{No}^{\mathrm{a}}$ & 530 & 96.36 & 29 & 93.55 & $0.66^{\mathrm{b}}$ & 1.83 & 0.41 & 8.20 \\
\hline & Yes & 20 & 3.64 & 2 & 6.45 & & & & \\
\hline \multirow{2}{*}{ Do you know how to avoid parasitic infection? } & No & 346 & 62.91 & 21 & 67.74 & $0.59^{c}$ & 0.81 & 0.37 & 1.75 \\
\hline & Yes $^{\mathrm{a}}$ & 204 & 37.09 & 10 & 32.26 & & & & \\
\hline \multirow[t]{2}{*}{ No. of bathrooms in house } & 1 & 101 & 18.36 & 4 & 12.9 & $0.44^{c}$ & 1.52 & 0.52 & 4.43 \\
\hline & $>1$ & 449 & 81.64 & 27 & 87.1 & & & & \\
\hline \multirow[t]{2}{*}{ Student washes hands before and after meals } & No & 23 & 4.18 & 1 & 3.25 & $0.99^{\mathrm{b}}$ & 1.35 & 0.17 & 10.35 \\
\hline & Yes $^{\mathrm{a}}$ & 527 & 95.82 & 30 & 96.77 & & & & \\
\hline \multirow[t]{2}{*}{ Student washes hands after bathroom use } & No & 9 & 1.64 & 0 & 0.00 & $0.99^{b}$ & N/A & & \\
\hline & $\mathrm{Yes}^{\mathrm{a}}$ & 541 & 98.36 & 31 & 100.0 & & & & \\
\hline \multirow[t]{2}{*}{ How do you wash hands? } & Water only & 74 & 13.45 & 9 & 29.03 & $0.03^{\mathrm{b}}$ & 2.63 & 1.17 & 5.93 \\
\hline & Water and soap ${ }^{\mathrm{a}}$ & 476 & 86.55 & 22 & 70.97 & $0.031^{\mathrm{d}}$ & $2.47^{\mathrm{d}}$ & $1.09^{\mathrm{d}}$ & $5.61^{\mathrm{d}}$ \\
\hline \multirow{2}{*}{$\begin{array}{l}\text { Do you wash vegetables and fruits well } \\
\text { before eating? }\end{array}$} & No & 4 & 0.73 & 0 & 0 & $0.99^{\mathrm{b}}$ & N/A & & \\
\hline & Yes $^{\mathrm{a}}$ & 546 & 99.27 & 31 & 100 & & & & \\
\hline \multirow[t]{2}{*}{ Does student has habit of nail biting } & $\mathrm{No}^{\mathrm{a}}$ & 398 & 72.36 & 20 & 64.52 & $0.35^{\mathrm{c}}$ & 0.69 & 0.32 & 1.48 \\
\hline & Yes & 152 & 27.64 & 11 & 35.48 & & & & \\
\hline \multirow{2}{*}{ Does student has habit of finger sucking } & $\mathrm{No}^{\mathrm{a}}$ & 522 & 94.91 & 30 & 96.77 & $0.99^{\mathrm{b}}$ & 1.61 & 0.21 & 12.20 \\
\hline & Yes & 28 & 5.09 & 1 & 3.23 & & & & \\
\hline \multirow[t]{2}{*}{ Does student has habit of walking bare footed } & $\mathrm{No}^{\mathrm{a}}$ & 377 & 68.55 & 19 & 61.29 & $0.40^{c}$ & 0.73 & 0.34 & 1.53 \\
\hline & Yes & 173 & 31.45 & 12 & 38.71 & & & & \\
\hline
\end{tabular}

aReference category; ' Fisher's exact test; ' $\chi^{2}$ test; ${ }^{\mathrm{d}}$ Adjusted for age and gender; CI, confidence interval; LCL, lower confidence limit; N/A, not applicable; OR, odds ratio; UCL, upper confidence limit.

Table 5 Linear regression for the effect of intestinal parasitic infections on weight, height, and MUAC adjusted for age

\begin{tabular}{lccccccc}
\hline & & & & & \multicolumn{2}{c}{$95 \% \mathrm{CI}$} \\
\cline { 6 - 7 } $\begin{array}{l}\text { Dependent } \\
\text { variable }\end{array}$ & $\boldsymbol{B}^{\mathrm{a}}$ & SE & $\boldsymbol{t}$ & Sig. & $\begin{array}{c}\text { Lower } \\
\text { bound }\end{array}$ & $\begin{array}{c}\text { Upper } \\
\text { bound }\end{array}$ \\
\hline Weight $(\mathrm{kg})$ & -3.943 & 2.613 & 1.509 & 0.132 & -1.189 & 9.076 \\
Height $(\mathrm{cm})$ & -1.751 & 1.757 & 0.996 & 0.319 & -1.700 & 5.201 \\
MUAC $(\mathrm{cm})$ & -1.260 & 1.274 & 0.989 & 0.323 & -1.243 & 3.762 \\
\hline
\end{tabular}

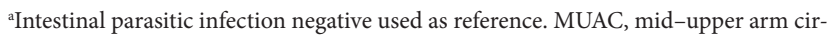
cumference; SE, standard error; Sig., significance.

of Blastocystis in causing disease is controversial and B. hominis seems to be a common but neglected parasite that should be treated, especially if it is the only detected organism associated with GI symptoms after careful search for other possible causes of symptoms. Most important is that a high prevalence of $B$. hominis in some countries raises the possibility of contamination of food or water supplies and poor hygiene.

The second most common intestinal parasite detected in the current study was G. lamblia, with a prevalence of $\sim 1 \%$ but this is lower than the prevalence recorded in many previous Saudi studies [15-18]. In this study, diarrhea and anorexia were only reported in one and three cases of G. lamblia infection, respectively. This may be related to the fact that giardiasis occurs in both asymptomatic and symptomatic disease including nausea, colicky abdominal pain, and acute diarrhea. It can also cause malabsorption with chronic diarrhea and failure to thrive in children [27].
In this study, low prevalence of $<1 \%$ was detected for other protozoa: E. nana (five cases, $0.9 \%$ ), E. coli (four cases, $0.7 \%$ ), and $C$. mesnili (one case, $0.2 \%$ ). The prevalence of these three parasites was lower than their prevalence in patients attending three hospitals in Jeddah City [28]. These IPIs were associated with RAP in three cases of E. coli and one case of E. nana. This low prevalence can indicate improvements in environmental living conditions of school children, while lack of symptoms may indicate nonsignificant infection, host immunocompetence, or the existence of asymptomatic carriers; a common phenomenon for many GI protozoa [29]. This concept of absence of correlations between clinical GI symptoms and IPIs was also evident in a previous Saudi study [18]. The lack of symptoms in many IPIs also points to the importance of periodic stool analysis by experts in this field as a screening method for accurate detection of asymptomatic carriers and prevalence of IPIs from time to time.

We found nonsignificant differences between children with and without IPIs regarding all studied demographic and socioeconomic risk factors. The lack of correlation between IPIs and various studied risk factors or morbidity indicators is largely due to the low number of IPIs detected, especially those with pathogenic capacity.

Significantly higher risk of IPIs was associated with drinking desalinated municipal water from tanks. The same risk factor has been similarly reported in previous Saudi studies $[16,18]$. In Jeddah, desalinated water is seawater that is transported in vehicles from stations to houses. It is poured in underground tanks then elevated by electrical water pumps to tanks on the roof to be let down to the house. The significant association between the use of desalinated water and IPIs revealed in this study may 
be explained by the lack of regular cleaning of the water tanks due to technical difficulties.

The other significant risk factor associated with IPIs was washing hands with only water. Thus, proper hand washing with water and soap is an important preventive measure that should be emphasized during the local health education programs for prevention of IPIs.

Although IPIs in children are associated with malnutrition, growth retardation, and learning disabilities [5,11,12], IPIs did not have an adverse impact on growth status or academic performance of school children in this study. This may be explained by the finding of non significant IPIs that were either asymptomatic or clinically mild and of short duration to adversely affect the growth status or academic performance of school children. Moreover, helminthic infections, which are mostly affecting growth and school performance, were basically absent.

It is worth mentioning that this study had some unique features. It was a comprehensive study including almost all risk factors for IPIs and had a representative sample of the population of children in our locality with a high study power of $85 \%$. Also, the design of this crosssectional comparative study and calculations of ORs allowed for better estimation of the role of each risk factor associated with IPIs.

\section{CONCLUSION}

The significant decline in the prevalence of IPIs in school children from $9.5 \%$ in 2004 to $5.3 \%$ in 2016 most probably reflects better awareness of population and remarkable improvements in socioeconomic, environmental, and hygienic living conditions of school children in Jeddah. Almost all detected IPIs were protozoal infections with $B$. hominis and $G$. lamblia as the most common, while helminthic infections were rare with only one $H$. nana infection. The only two significant risk factors associated with IPIs were drinking water from tanks and washing hands with only water. There was no significant impact of IPIs on growth parameters or academic performance of school children.

Despite the low prevalence of IPIs of $5.3 \%$ indicating outstanding improvements in environmental and hygienic living conditions of school children, more improvements can be achieved by providing more health education about prevention of IPIs (especially proper hand washing) in schools and school health units, improving socioeconomic standards, and giving more attention and care to drinking water with regular professional cleaning of tanks. Moreover, periodic screening with stool analysis may be the only way to detect cases and current prevalence of IPIs, as many cases are asymptomatic, or symptoms are nonspecific and could be associated with other GI problems.

\section{ACKNOWLEDGMENTS}

Authors would like to acknowledge with thanks Scientific Endowment of King Abdulaziz University (SE-KAU), Jeddah for financial support of this project. SE-KAU did not have any role in study design; in the collection, analysis or interpretation of data; or in the writing of the article.

\section{CONFLICTS OF INTEREST}

All authors declare no conflicts of interest.

\section{REFERENCES}

[1] Shakya B, Shrestha S, Madhikarmi NL, Adhikari R. Intestinal parasitic infection among school children. J Nepal Health Res Counc 2012;10;20-3.

[2] Niyizurugero E, Ndayanze JB, Bernard K. Prevalence of intestinal parasitic infections and associated risk factors among Kigali Institute of Education students in Kigali, Rwanda. Trop Biomed 2013;30;718-26.

[3] Barda BD, Rinaldi L, Ianniello D, Zepherine H, Salvo F, Sadutshang T, et al. Mini-FLOTAC, an innovative direct diagnostic technique for intestinal parasitic infections: experience from the field. PLoS Negl Trop Dis 2013;7;e2344.

[4] El-Sherbini GT, Abosdera MM. Risk factors associated with intestinal parasitic infections among children. J Egypt Soc Parasitol 2013;43;287-94.

[5] Wang X, Zhang L, Luo R, Wang G, Chen Y, Medina A, et al. Soiltransmitted helminth infections and correlated risk factors in preschool and school-aged children in rural Southwest China. PLoS One 2012;7:e45939.

[6] Barry MA, Weatherhead JE, Hotez PJ, Woc-Colburn L. Childhood parasitic infections endemic to the United States. Pediatr Clin North Am 2013;60;471-85.

[7] Nguyen NL, Gelaye B, Aboset N, Kumie A, Williams MA, Berhane Y. Intestinal parasitic infection and nutritional status among school children in Angolela, Ethiopia. J Prev Med Hyg 2012;53;157-64.

[8] Nxasana N, Baba K, Bhat V, Vasaikar S. Prevalence of intestinal parasites in primary school children of Mthatha, Eastern Cape province, South Africa. Ann Med Health Sci Res 2013;3: $511-6$.

[9] Sah RB, Bhattarai S, Yadav S, Baral R, Jha N, Pokharel PK. A study of prevalence of intestinal parasites and associated risk factors among the school children of Itahari, Eastern Region of Nepal. Trop Parasitol 2013;3:140-4.

[10] Tulu B, Taye S, Amsalu E. Prevalence and its associated risk factors of intestinal parasitic infections among Yadot primary school children of South Eastern Ethiopia: a cross-sectional study. BMC Res Notes 2014;7:848.

[11] Verhagen LM, Incani RN, Franco CR, Ugarte A, Cadenas Y, Sierra Ruiz CI, et al. High malnutrition rate in Venezuelan Yanomami compared to Warao Amerindians and Creoles: significant associations with intestinal parasites and anemia. PLoS One 2013;8:e77581.

[12] Papier K, Williams GM, Luceres-Catubig R, Ahmed F, Olveda RM, McManus DP, et al. Childhood malnutrition and parasitic helminth interactions. Clin Infect Dis 2014;59;234-43.

[13] Taylor-Robinson DC, Maayan N, Soares-Weiser K, Donegan S, Garner P. Deworming drugs for soil-transmitted intestinal worms in children: effects on nutritional indicators, haemoglobin and school performance. Cochrane Database Syst Rev 2012;11;CD000371.

[14] Ahmed MM, el Hady HM, Morsy TA. Parasitic infections and haemoglobin level among school children of different 
socioeconomic classes in Abha, Saudi Arabia. J Egypt Soc Parasitol 1990;20;61-7.

[15] Omar MS, Abu-Zeid HA, Mahfouz AA. Intestinal parasitic infections in schoolchildren of Abha (Asir), Saudi Arabia. Acta Trop 1991;48;195-202.

[16] Al-Shammari S, Khoja T, El-Khwasky F, Gad A. Intestinal parasitic diseases in Riyadh, Saudi Arabia: prevalence, sociodemographic and environmental associates. Trop Med Int Health 2001;6:184-9.

[17] el-Sheikh SM, el-Assouli SM. Prevalence of viral, bacterial and parasitic enteropathogens among young children with acute diarrhoea in Jeddah, Saudi Arabia. J Health Popul Nutr 2001;19;25-30.

[18] Zakai HA. Intestinal parasitic infections among primary school children in Jeddah, Saudi Arabia. J Egypt Soc Parasitol 2004;34;783-90.

[19] Hegazi MA, Patel TA, El-Deek BS. Prevalence and characters of Entamoeba histolytica infection in Saudi infants and children admitted with diarrhea at 2 main hospitals at South Jeddah: a re-emerging serious infection with unusual presentation. Braz J Infect Dis 2013;17;32-40.

[20] Chow SC, Shao J, Wang H. Exact tests for proportion. In: Chow SC, Shao J, Wang H, editors. Sample size calculations in clinical research, New York: Marcel Dekker; 2003, pp. 115-122.

[21] Qadri SM, al-Okaili GA, al-Dayel F. Clinical significance of Blastocystis hominis. J Clin Microbiol 1989;27;2407-9.

[22] Beyhan YE, Yilmaz H, Cengiz ZT, Ekici A. Clinical significance and prevalence of Blastocystis hominis in Van, Turkey. Saudi Med J 2015;36;1118-21.
[23] El Safadi D, Gaayeb L, Meloni D, Cian A, Poirier P, Wawrzyniak I, et al. Children of Senegal River Basin show the highest prevalence of Blastocystis sp. ever observed worldwide. BMC Infect Dis $2014 ; 14 ; 164$

[24] Jones MS, Whipps CM, Ganac RD, Hudson NR, Boorom K. Association of Blastocystis subtype 3 and 1 with patients from an Oregon community presenting with chronic gastrointestinal illness. Parasitol Res 2009;104;341-5.

[25] Stensvold CR, Lewis HC, Hammerum AM, Porsbo LJ, Nielsen SS, Olsen KE, et al. Blastocystis: unravelling potential risk factors and clinical significance of a common but neglected parasite. Epidemiol Infect 2009;137;1655-63.

[26] Kurt Ö, Funda Doğruman Al, Tanyüksel M. Eradication of Blastocystis in humans: really necessary for all? Parasitol Int 2016;65;797-801.

[27] Solaymani-Mohammadi S, Singer SM. Giardia duodenalis: the double-edged sword of immune responses in Giardiasis. Exp Parasitol 2010;126;292-7.

[28] Barnawi AB, Tonkal AM, Fouad MA, Al-Braiken FA. Detection of Entamoeba histolytica/dispar in stool specimens by using enzyme-linked immunosorbent assay in the population of Jeddah City, Saudi Arabia. J Egypt Soc Parasitol 2007;37; $143-50$.

[29] Osman M, El Safadi D, Cian A, Benamrouz S, Nourrisson C, Poirier $\mathrm{P}$, et al. Prevalence and risk factors for intestinal protozoan infections with Cryptosporidium, Giardia, Blastocystis and Dientamoeba among schoolchildren in Tripoli, Lebanon. PLoS Negl Trop Dis 2016;10;e0004496. 